\title{
Effect of postoperative analgesia technique on the prognosis of gastric cancer: a retrospective analysis
}

\author{
Seokyung Shin ${ }^{1}$, Hyoung-Il Kim², Na Young Kim', Ki-Young Lee ${ }^{1}$, Dong Wook Kim³ \\ and Young Chul Yoo ${ }^{1}$ \\ ${ }^{1}$ Department of Anesthesiology and Pain Medicine, Severance Hospital, Anesthesia and Pain Research Institute, Yonsei \\ University College of Medicine, Seodaemun-gu, Seoul 03722, Korea \\ ${ }^{2}$ Department of Surgery, Yonsei University College of Medicine, Seodaemun-gu, Seoul 03722, Korea \\ ${ }^{3}$ Department of Policy Research Affairs, National Health Insurance Service Ilsan Hospital, Ilsan-donggu, Goyang-si, Gyeonggi- \\ do 10444, Korea
}

Correspondence to: Dong Wook Kim, email: kimdw2269@gmail.com

Young Chul Yoo, email: seaoyster@yuhs.ac

Keywords: analgesia, epidural, analgesia, patient controlled, gastric cancer

Received: July 07, 2017 Accepted: September 25, $2017 \quad$ Published: October 20, 2017

Copyright: Shin et al. This is an open-access article distributed under the terms of the Creative Commons Attribution License 3.0 (CC BY $3.0)$, which permits unrestricted use, distribution, and reproduction in any medium, provided the original author and source are credited.

\section{ABSTRACT}

Background: Whether regional analgesia techniques have favorable impact on prognosis after cancer surgery is unclear, and existing reports show controversial results. The aim of the present study was to evaluate and compare recurrence and mortality between patients that received either intravenous (IV) or epidural patient controlled analgesia (PCA) for pain control after curative surgery for gastric cancer.

Materials and methods: Medical records of patients that underwent curative gastrectomy for gastric cancer between November 2005 and December 2010 were reviewed. Identified patients were categorized according to the use of IV or epidural PCA for postoperative analgesia. Demographic and perioperative variables including type of PCA were analyzed by univariate and multiple regression analysis to investigate any association with recurrence and mortality after surgery. Propensity score matching was done to adjust for selection bias.

Results: Of the 3,799 patients included in this analysis, 374 and 3, 425 patients received IV and epidural PCAs, respectively. No difference in recurrence (HR, 1.092; 95\% CI 0.859 to $1.388 ; P=0.471$ ) or mortality (HR, $0.695 ; 95 \%$ CI 0.429 to 1.125 ; $P=0.138$ ) was identified between the use of IV and epidural PCA. Propensity score matching also showed no difference in recurrence (HR, 1.098; 95\% CI 0.756 to 1.596; $P=0.623)$ or mortality $(\mathrm{HR}, 0.855 ; 95 \% \mathrm{CI} 0.391$ to $1.869 ; P=0.695)$ between the two groups.

Conclusions: Postoperative use of epidural analgesia was not found to be associated with reduced recurrence or mortality after curative surgery in gastric cancer patients. This finding needs to be confirmed with prospective studies in the future.

\section{INTRODUCTION}

The notion that perioperative regional anesthesia and analgesia may improve cancer prognosis first emerged roughly a decade ago, [1-3] and was met by genuine enthusiasm of the anesthesia society. However, a decade later, we are still at a shortage of meaningful evidence to either support or refute this hypothesis. The difficulty of performing a large scale randomized controlled trial (RCT) with a relatively long follow-up period has led us to first look at the available data, and we have been presented with a number of retrospective $[1,2,4-15]$ and very few 
prospective $[6,16]$ studies done on the effect of regional anesthesia and/or analgesia on the prognosis of different types of cancer.

Among several regional techniques, epidural analgesia is the most commonly employed method for operations performed in the abdominopelvic region. While there is relative abundance of retrospective and observational studies done on the effect of epidural analgesia in prostate $[1,5,6,8,17-20]$ and colorectal cancer, [12, 13, 21-24] there are only a few that investigate gastric cancer, $[4,14,15,25]$ despite it being the fifth most common cancer worldwide. Moreover, not only do the existing studies report inconsistent results, most are based on the data of an insufficient number of a rather heterogeneous group of patients. The primary goal of this retrospective study was to compare the effect of postoperative epidural patient-controlled analgesia (PCA) vs. intravenous (IV) PCA, on recurrence and mortality in patients that received curative surgery with homogeneous surgical treatment at a high-volume center.

\section{RESULTS}

\section{Study population, demographic data and perioperative characteristics}

Figure 1 shows the flowchart of patient sample selection. The data of 4, 098 patients were reviewed for analysis. Among these patients, 106 cases that received preoperative chemotherapy and 171 cases that underwent non-curative surgery were excluded. Additionally, 6 cases of laparoscopic gastrectomy that were converted to laparotomy, 3 cases of unclear analgesia method, and 13 cases of patient death within 30 days after surgery were excluded from analysis.

The remaining 3, 799 cases with 374 in the IV PCA group and 3, 425 in Epidural PCA group were compared and analyzed. The opioid used in both type of PCAs was fentanyl, and all epidural PCAs contained ropivacaine. Ropivacaine was infused at a concentration of $0.15 \%$ and mixed with fentanyl at a dose of between 2-4 $\mu \mathrm{g} /$ $\mathrm{mL}$ at basal rates of $4-5 \mathrm{~mL} / \mathrm{hr}$, bolus doses of $1-2 \mathrm{~mL}$, and lock-out times of 15 minutes. All patients were anesthetized with balanced anesthesia which consisted of the use of a volatile anesthetic and remifentanil infusion at rates between $0.1-0.3 \mathrm{mcg} / \mathrm{kg} / \mathrm{min}$. Demographic characteristics of the patients are listed in Table 1. When comparing the demographic characteristics between the two groups, there was no difference in sex, height, weight, presence of hypertension, pulmonary, and liver diseases. However, there was a significant difference in age, and the presence of DM, cardiac, renal and neurologic diseases between the two groups. Greater cancer recurrence was seen with higher cancer stage $(P=0.012)$, but no difference was observed in tumor histology or resection method between the two groups.
Enflurane, isoflurane and $\mathrm{N}_{2} \mathrm{O}$ were anesthetics that were more often used in the Epidural PCA group, while sevoflurane was more commonly used in the IV PCA group. Among other perioperative characteristics, a significantly greater proportion of patients of the IV PCA group were found to receive NSAIDs, phenylephrine, esmolol, labetalol and nicardipine than the Epidural PCA group, while ephedrine was more commonly used in the Epidural PCA group. There was no difference in intraoperative administration of colloids or packed RBC. Patients were followed up after surgery once every 3 months during the first year, every 6 months for the following 2 years, and every year thereafter for the duration of the scheduled follow-up period. Cancer recurrence occurred in $81(21.7 \%)$ patients of the IV PCA group and $585(17.1 \%)$ patients of the Epidural PCA group, and the mean time to recurrence was $564.34 \pm$ 404.0 and 545.2 \pm 452.7 days in the IV PCA and Epidural PCA groups, respectively, with no significant difference $(P=0.717)$. Mortality occurred in $90(24.1 \%)$ and 641 $(18.7 \%)$ patients of the IV PCA and Epidural PCA groups, respectively. The mean follow-up time in all of the patients was $53.3 \pm 21.7$ months.

\section{Association between analgesia method and cancer recurrence and mortality after surgery}

Kaplan-Meier curves for recurrence and mortality of patients with IV PCA vs. epidural PCA are shown in Figure 2.

Neither IV nor epidural PCA was found to be associated with cancer recurrence after surgery (HR, 1.092; $95 \% \mathrm{CI}, 0.859$ to $1.388 ; P=0.471$ ) (Table 2). Factors that were related to lower recurrence were younger age and lower cancer stage. Total gastrectomy was found to be associated with greater risk of recurrence compared to subtotal gastrectomy (HR, $1.333 ; 95 \% \mathrm{CI}, 1.132$ to 1.569 ; $P=0.001)$. None of the anesthetics or other perioperative drugs were found to be associated with cancer recurrence. Type of postoperative PCA was also not found to be associated with mortality after open gastrectomy $(P=$ 0.138 ) (Table 3). Other variables associated with greater mortality included older age, higher cancer stage, total gastrectomy and the administration of intraoperative phenylephrine, norepinephrine and labetalol.

In our PSM analysis, there was no difference in recurrence and mortality between the two groups $(P=$ 0.623 and $P=0.695$, respectively) (Table 4).

\section{DISCUSSION}

The perioperative period during which the patient is in the hands of the anesthesiologist is considered as a narrow window of opportunity where outcome after surgery may be affected by the choice of drugs and method of anesthesia and/or analgesia. [26] While 
Table 1: Demographic and perioperative characteristics

\begin{tabular}{|c|c|c|c|}
\hline & $\begin{array}{c}\text { IV PCA } \\
(n=374)\end{array}$ & $\begin{array}{c}\text { Epidural PCA } \\
(n=3,425)\end{array}$ & $P$-value \\
\hline Age (years) & $59.6 \pm 11.6$ & $57.5 \pm 11.7$ & 0.001 \\
\hline Male sex, $\mathrm{n}$ & $242(64.7)$ & $2,280(66.6)$ & 0.489 \\
\hline Height (cm) & $163.4 \pm 8.3$ & $164.0 \pm 8.6$ & 0.187 \\
\hline Weight (kg) & $62.8 \pm 11.0$ & $62.6 \pm 10.0$ & 0.678 \\
\hline \multicolumn{4}{|l|}{ Comorbidities } \\
\hline HTN & $108(28.9)$ & $916(26.7)$ & 0.390 \\
\hline DM & $64(17.1)$ & $398(11.6)$ & 0.003 \\
\hline Pulmonary disease ${ }^{*}$ & $8(2.1)$ & $58(1.7)$ & 0.529 \\
\hline Cardiac disease $^{\dagger}$ & $35(9.4)$ & $102(3.0)$ & $<0.001$ \\
\hline Renal disease & $16(4.3)$ & $23(0.7)$ & $<0.001$ \\
\hline Liver disease $\S$ & $20(5.3)$ & $141(4.1)$ & 0.278 \\
\hline Neurologic disease ${ }^{\| l}$ & $21(5.6)$ & $47(1.4)$ & $<0.001$ \\
\hline Cancer stage & & & 0.012 \\
\hline I & $175(46.8)$ & $1,867(54.5)$ & \\
\hline II & $83(22.2)$ & $605(17.7)$ & \\
\hline III & $116(31.0)$ & $953(27.8)$ & \\
\hline Tumor histology & & & 0.052 \\
\hline AWD & $38(10.2)$ & $416(12.1)$ & \\
\hline AMD & $114(30.5)$ & $988(28.8)$ & \\
\hline APD & $132(35.3)$ & $1126(32.9)$ & \\
\hline Mucinous & $11(2.9)$ & $87(2.5)$ & \\
\hline $\mathrm{SRC}$ & $61(16.3)$ & $716(20.9)$ & \\
\hline Other & $18(4.8)$ & $92(2.7)$ & \\
\hline Lymphovascular invasion & $130(34.8)$ & $1216(35.5)$ & 0.820 \\
\hline Resection method & & & 0.241 \\
\hline Subtotal & $265(70.9)$ & $2,527(73.8)$ & \\
\hline Total & $109(29.1)$ & $898(26.2)$ & \\
\hline \multicolumn{4}{|l|}{ Anesthetic } \\
\hline Desflurane & $67(17.9)$ & $492(14.4)$ & 0.077 \\
\hline Enflurane & $0(0)$ & $70(2.0)$ & 0.002 \\
\hline Isoflurane & $87(23.3)$ & $1,032(30.1)$ & 0.006 \\
\hline Sevoflurane & $220(58.8)$ & $1,825(53.3)$ & 0.043 \\
\hline $\mathrm{N} 2 \mathrm{O}$ & $14(3.7)$ & $439(12.8)$ & $<0.001$ \\
\hline Propofol 1\% & $295(78.9)$ & $2,608(76.1)$ & 0.249 \\
\hline Thiopental sodium & $76(20.3)$ & $763(22.3)$ & 0.431 \\
\hline \multicolumn{4}{|l|}{ Other perioperative drugs } \\
\hline Aspirin & $2(0.5)$ & $7(0.2)$ & 0.220 \\
\hline NSAIDs & $225(60.2)$ & $1229(35.9)$ & $<0.001$ \\
\hline Ephedrine & $99(26.5)$ & $1,337(39.0)$ & $<0.001$ \\
\hline Phenylephrine & $33(8.8)$ & $167(4.9)$ & 0.002 \\
\hline Norepinephrine & $4(1.1)$ & $25(0.7)$ & 0.523 \\
\hline Esmolol & $27(7.2)$ & $139(4.1)$ & 0.007 \\
\hline Labetalol & $21(5.6)$ & $55(1.6)$ & $<0.001$ \\
\hline Nicardipine & $25(6.7)$ & $77(2.2)$ & $<0.001$ \\
\hline
\end{tabular}


Intraoperative fluid

$\begin{array}{lccr}\text { Colloid } & 62(16.6) & 561(16.4) & 0.941 \\ \text { Packed RBC } & 8(2.1) & 65(1.9) & 0.692 \\ \text { Recurrence } & 81(21.7) & 585(17.1) & 0.031 \\ \text { Mortality } & 90(24.1) & 641(18.7) & 0.015\end{array}$

Values are mean $\pm \mathrm{SD}$ or $n(\%)$ of patients, HTN $=$ hypertension, DM $=$ diabetes mellitus

AWD = adenocarcinoma, well differentiated, AMD = adenocarcinoma, moderately differentiated, APD = adenocarcinoma, poorly differentiated, $\mathrm{SRC}=$ signet ring cell. Pulmonary disease ${ }^{*}=$ History of pulmonary diseases, Cardiac disease ${ }^{\dagger}=$ History

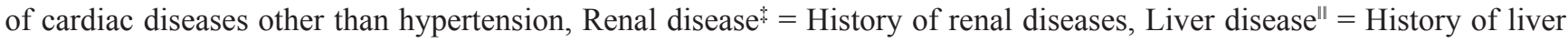
diseases, Neurologic disease ${ }^{\| l}=$ History of neurologic diseases including cerebrovascular accidents.

surgical resection of the primary tumor can be ultimately curative, it also exposes the patient to an immunologically vulnerable period during which the patient is relatively more prone to undetectable residual disease or micrometastasis. [27] Although it is still largely under debate, neuraxial techniques have been suggested to be able to improve prognosis after cancer surgery. However, the findings of the present retrospective analysis show otherwise, where we failed to find any difference in recurrence or mortality after curative surgery for gastric cancer between patients that received either IV or epidural PCA for postoperative analgesia.

Proposed mechanisms through which regional anesthesia and analgesia may influence cancer outcome can be summarized into "immunomodulation" and "anti-inflammation". The immunomodulatory and antiinflammatory effects of regional anesthesia and analgesia can be thought of as the combined output of several different mechanisms which include the attenuation of sympathetic nervous system stimulation in response to surgical stress and postoperative pain, the sparing of the need of opioids and therefore the immunosuppressant effects of such drugs, and the direct cytotoxic and antiinflammatory effects of amide local anesthetics such as ropivacaine which was used in all of the patients included in our analysis. [27, 28].

However, whether the aforementioned immunomodulatory and anti-inflammatory effects of neuraxial techniques actually translate into a positive effect on cancer outcome is not clear, and the existing evidence present conflicting results in various types of cancer. [27] This is also true for gastric cancer, where epidural anesthesia and/or analgesia are commonly used. A rare randomized trial that studied the effect of epidural analgesia on cancer prognosis after major abdominal surgery concluded that cancer recurrence and mortality rates were not different between patients that received general anesthesia combined with epidural anesthesia

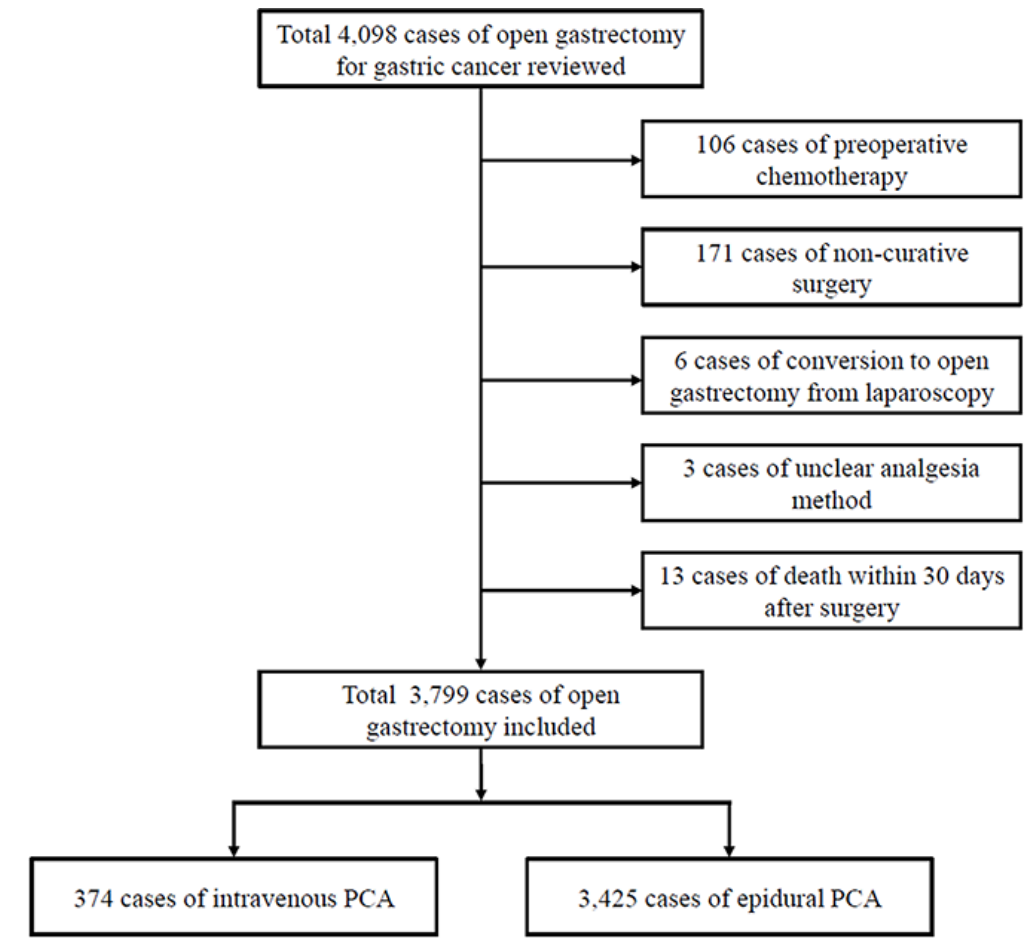

Figure 1: Flowchart of patient sample selection. 
Table 2: Univariate and multiple regression analysis of variables associated with recurrence after open gastrectomy for gastric cancer

\begin{tabular}{|c|c|c|c|c|}
\hline & \multicolumn{2}{|c|}{ Univariate Analysis } & \multicolumn{2}{|c|}{ Multiple Analysis } \\
\hline & $\begin{array}{c}\text { Hazard Ratio }(95 \% \\
\text { CI) }\end{array}$ & $P$-value & Hazard Ratio (95\% CI) & $P$-value \\
\hline \multicolumn{5}{|l|}{ PCA type } \\
\hline Intravenous & 1 & & 1 & \\
\hline Epidural & $1.032(0.818-1.303)$ & 0.789 & $1.092(0.859-1.388)$ & 0.471 \\
\hline Age & $1.009(1.002-1.015)$ & 0.007 & $1.012(1.005-1.020)$ & 0.001 \\
\hline \multicolumn{5}{|l|}{ Sex } \\
\hline Male & 1 & & 1 & \\
\hline Female & $0.961(0.815-1.133)$ & 0.637 & $1.014(0.834-1.232)$ & 0.893 \\
\hline Height & $0.997(0.987-1.007)$ & 0.545 & $0.981(0.954-1.010)$ & 0.202 \\
\hline Weight & $1.002(0.994-1.009)$ & 0.671 & $1.005(0.996-1.014)$ & 0.288 \\
\hline \multicolumn{5}{|l|}{ Comorbidities } \\
\hline HTN & $1.116(0.935-1.333)$ & 0.225 & $0.974(0.800-1.185)$ & 0.790 \\
\hline $\mathrm{DM}$ & $1.114(0.898-1.383)$ & 0.325 & $0.975(0.772-1.231)$ & 0.829 \\
\hline \multicolumn{5}{|l|}{ Cancer stage } \\
\hline I & 1 & & 1 & \\
\hline II & $1.364(0.965-1.927)$ & 0.078 & $1.330(0.936-1.890)$ & 0.112 \\
\hline III & $1.867(1.378-2.528)$ & $<0.0001$ & $1.733(1.266-2.372)$ & $<0.001$ \\
\hline \multicolumn{5}{|l|}{ Tumor histology } \\
\hline AWD & 1 & & & \\
\hline AMD & $0.876(0.693-1.106)$ & 0.266 & & \\
\hline APD & $0.910(0.724-1.143)$ & 0.417 & & \\
\hline Mucinous & $1.081(0.688-1.699)$ & 0.735 & & \\
\hline SRC & $0.884(0.690-1.133)$ & 0.330 & & \\
\hline Other & $0.861(0.544-1.365)$ & 0.525 & & \\
\hline Lymphovascular invasion & $0.973(0.840-1.126)$ & 0.714 & & \\
\hline \multicolumn{5}{|l|}{ Resection method } \\
\hline Subtotal & 1 & & 1 & \\
\hline Total & $1.302(1.115-1.520)$ & 0.001 & $1.308(1.112-1.538)$ & 0.001 \\
\hline \multicolumn{5}{|l|}{ Anesthetic } \\
\hline Desflurane & $1.140(0.919-1.415)$ & 0.233 & & \\
\hline Enflurane & $0.474(0.273-0.824)$ & 0.008 & $0.603(0.340-1.072)$ & 0.085 \\
\hline Isoflurane & $1.050(0.887-1.243)$ & 0.569 & & \\
\hline Sevoflurane & $0.980(0.841-1.142)$ & 0.794 & & \\
\hline $\mathrm{N} 2 \mathrm{O}$ & $0.747(0.590-0.945)$ & 0.015 & $0.823(0.643-1.052)$ & 0.120 \\
\hline Propofol 1\% & $1.115(0.934-1.331)$ & 0.228 & & \\
\hline Thiopental sodium & $0.894(0.746-1.072)$ & 0.226 & & \\
\hline \multicolumn{5}{|l|}{ Other perioperative drugs } \\
\hline Aspirin & $1.031(0.257-4.129)$ & 0.966 & & \\
\hline NSAIDs & $0.905(0.783-1.045)$ & 0.174 & & \\
\hline Ephedrine & $1.106(0.946-1.292)$ & 0.208 & & \\
\hline Phenylephrine & $1.442(1.045-1.989)$ & 0.026 & $1.255(0.893-1.763)$ & 0.192 \\
\hline
\end{tabular}




\begin{tabular}{lllll}
$\quad$ Norepinephrine & $2.953(1.219-7.153)$ & 0.016 & $1.866(0.685-5.082)$ & 0.222 \\
Esmolol & $1.380(0.990-1.924)$ & 0.058 & & \\
$\quad$ Labetalol & $1.222(0.673-2.221)$ & 0.501 & & \\
$\quad$ Nicardipine & $1.570(0.940-2.624)$ & 0.085 & $1.454(0.859-2.460)$ & \\
Intraoperative fluid & & & \\
$\quad$ Colloid & $1.076(0.892-1.297)$ & 0.444 & \\
$\quad$ Packed RBC & $1.097(0.735-1.637)$ & 0.650 & & \\
\hline
\end{tabular}

$\mathrm{CI}=$ Confidence Interval PCA $=$ patient controlled analgesia, $\mathrm{HTN}=$ hypertension, $\mathrm{DM}=$ diabetes mellitus, $\mathrm{RBC}=$ red blood cells.

and analgesia, compared to those that received general anesthesia with opioid analgesia. [16] However, the proportion of patients with gastric cancer was lower than $15 \%$ overall, and approximately $50 \%$ of patients were those with colorectal cancer. It is difficult to generalize its results mainly due to the fact that tumor biology varies significantly between organs. Also, while this study is significant in that it is probably the only randomized trial to date that studied the effect of epidural block with follow-up results up to 5 years, the analysis itself was a retrospective review of follow-up data from a previous RCT.

Although gastric cancer is the fifth most common malignancy and the third leading cause of cancer death worldwide, due to its relative uncommonness in Northern America and Europe, studies conducted in gastric cancer patients are lacking in comparison to studies in colorectal, breast, prostate and ovarian cancer. As of today, the majority of existing retrospective studies report no association between epidural anesthesia and/or analgesia and gastric cancer prognosis. Hiller et al. [4] reported an association between postoperative epidural analgesia and benefit on cancer recurrence and survival following surgery for esophageal, but not gastric cancer in 2014. A similar study by Cummings et al. [25] also published in the same year reported no association between

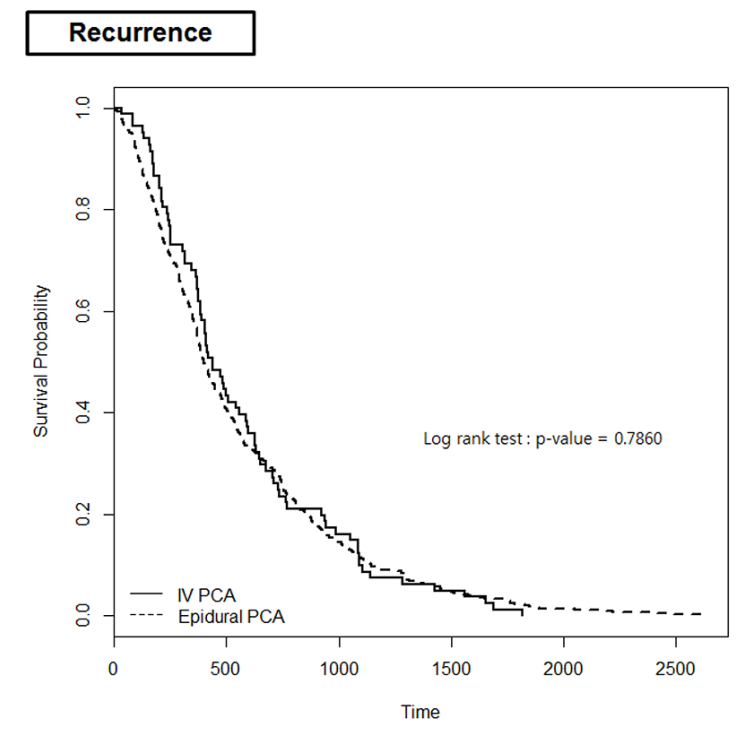

postoperative epidural analgesia and reduced recurrence or improved survival after resection in gastric cancer patients. These results somewhat dampened the earlier enthusiasm towards the possible ability of perioperative epidural techniques to modulate cancer recurrence. A more recent retrospective study that compared combined epidural and general anesthesia with general anesthesia alone, reported no difference in long-term survival in gastric cancer patients [14]. Interestingly, in contrast to the aforementioned negative reports, a recent retrospective study of 4,218 patients by Wang et al. [15] concluded that epidural anesthesia combined with general anesthesia and postoperative epidural PCA may be associated with improved survival after resection for gastric cancer. However, despite having the merit of a largest sample size to date, this study only looked at overall survival, but not cancer recurrence after surgery. Also, the majority of patients included in this study were of advanced stage (Stage I $=28.9 \%$, Stage II $=4.3 \%$, Stage III $=66.9 \%$ ), which may have affected their results. The patients of the present study showed a relatively more even distribution among cancer stages (Stage I $=53.8 \%$, Stage II $=18.1 \%$, Stage III $=28.1 \%$ ) compared to the previous retrospective analysis.

Our study is not the first retrospective analysis to report negative association between epidural analgesia

\section{Mortality}

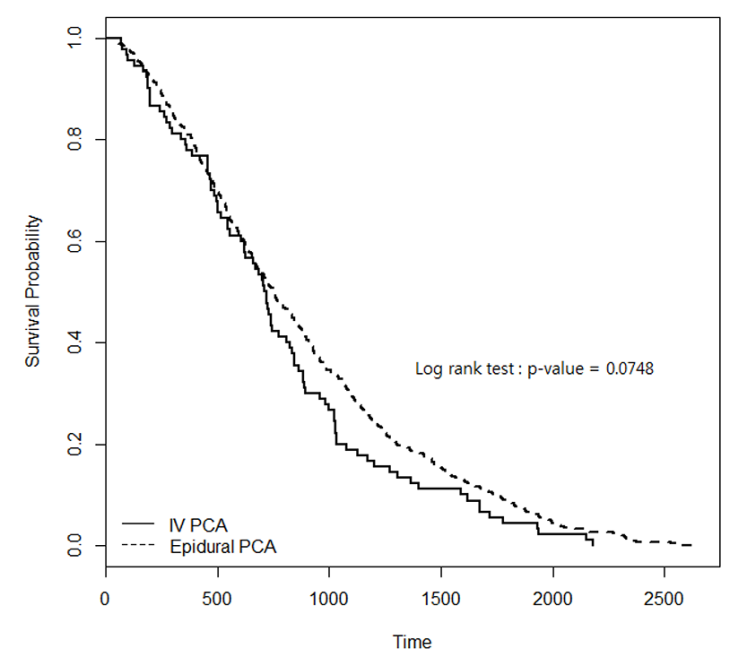

Figure 2: Kaplan-Meier curves for 5-year recurrence and mortality. 
Table 3: Univariate and multiple regression analysis of variables associated with mortality after open gastrectomy for gastric cancer

\begin{tabular}{|c|c|c|c|c|}
\hline & \multicolumn{2}{|c|}{ Univariate Analysis } & \multicolumn{2}{|c|}{ Multiple Analysis } \\
\hline & $\begin{array}{c}\text { Hazard Ratio (95\% } \\
\text { CI) }\end{array}$ & $P$-value & Hazard Ratio (95\% CI) & $P$-value \\
\hline \multicolumn{5}{|l|}{ PCA type } \\
\hline Intravenous & 1 & & 1 & \\
\hline Epidural & $0.818(0.655-1.021)$ & 0.075 & $0.695(0.429-1.125)$ & 0.138 \\
\hline Age & $1.007(1.001-1.013)$ & 0.030 & $1.015(1.003-1.027)$ & 0.016 \\
\hline \multicolumn{5}{|l|}{ Sex } \\
\hline Male & 1 & & 1 & \\
\hline Female & $1.110(0.945-1.304)$ & 0.205 & $0.905(0.590-1.389)$ & 0.649 \\
\hline Height & $0.990(0.981-0.999)$ & 0.028 & $0.989(0.964-1.014)$ & 0.385 \\
\hline Weight & $0.994(0.986-1.001)$ & 0.086 & $0.997(0.982-1.012)$ & 0.689 \\
\hline \multicolumn{5}{|l|}{ Comorbidities } \\
\hline HTN & $1.029(0.878-1.207)$ & 0.720 & $0.753(0.555-1.021)$ & 0.068 \\
\hline $\mathrm{DM}$ & $1.130(0.933-1.369)$ & 0.210 & $1.148(0.801-1.645)$ & 0.452 \\
\hline \multicolumn{5}{|l|}{ Cancer stage } \\
\hline I & 1 & & 1 & \\
\hline II & $1.338(1.016-1.762)$ & 0.038 & $1.745(1.146-2.657)$ & 0.009 \\
\hline III & $1.717(1.367-2.156)$ & $<0.0001$ & $2.193(1.476-3.257)$ & $<0.001$ \\
\hline \multicolumn{5}{|l|}{ Tumor histology } \\
\hline AWD & 1 & & & \\
\hline AMD & $0.949(0.663-1.358)$ & 0.774 & & \\
\hline APD & $1.220(0.860-1.731)$ & 0.265 & & \\
\hline Mucinous & $0.963(0.591-1.568)$ & 0.879 & & \\
\hline $\mathrm{SRC}$ & $1.157(0.795-1.684)$ & 0.447 & & \\
\hline Other & $1.103(0.651-1.867)$ & 0.715 & & \\
\hline Lymphovascular invasion & $1.198(1.024-1.401)$ & 0.025 & $0.865(0.657-1.139)$ & 0.302 \\
\hline \multicolumn{5}{|l|}{ Resection method } \\
\hline Subtotal & 1 & & 1 & \\
\hline Total & $1.350(1.165-1.565)$ & $<0.0001$ & $1.473(1.155-1.877)$ & 0.002 \\
\hline \multicolumn{5}{|l|}{ Anesthetic } \\
\hline Desflurane & $1.149(0.928-1.425)$ & 0.203 & & \\
\hline Enflurane & $0.418(0.235-0.745)$ & 0.003 & $0.549(0.297-1.012)$ & 0.055 \\
\hline Isoflurane & $0.921(0.782-1.083)$ & 0.318 & & \\
\hline Sevoflurane & $1.118(0.964-1.296)$ & 0.140 & & \\
\hline $\mathrm{N} 2 \mathrm{O}$ & $0.761(0.610-0.950)$ & 0.016 & $1.087(0.824-1.433)$ & 0.556 \\
\hline Propofol 1\% & $1.017(0.864-1.198)$ & 0.837 & & \\
\hline Thiopental sodium & $1.059(0.895-1.252)$ & 0.505 & & \\
\hline \multicolumn{5}{|l|}{ Other perioperative drugs } \\
\hline Aspirin & $1.535(0.493-4.775)$ & 0.459 & & \\
\hline NSAIDs & $0.846(0.729-0.981)$ & 0.027 & $1.074(0.838-1.376)$ & 0.573 \\
\hline Ephedrine & $1.151(0.993-1.334)$ & 0.063 & $1.076(0.836-1.385)$ & 0.569 \\
\hline Phenylephrine & $1.455(1.122-1.887)$ & 0.005 & $2.070(1.169-3.664)$ & 0.013 \\
\hline
\end{tabular}




\begin{tabular}{lllcl} 
Norepinephrine & $1.740(0.982-3.081)$ & 0.058 & $2.638(1.040-6.690)$ & 0.041 \\
Esmolol & $1.252(0.922-1.701)$ & 0.150 & & 0.027 \\
Labetalol & $1.904(1.099-3.299)$ & 0.022 & $10.623(1.31-86.135)$ & \\
$\quad$ Nicardipine & $1.366(0.865-2.156)$ & 0.181 & & 0.050 \\
Intraoperative fluid & & & & \\
$\quad$ Colloid & $0.859(0.724-1.020)$ & 0.083 & $0.758(0.575-0.999)$ & \\
Packed RBC & $1.300(0.929-1.818)$ & 0.126 & & \\
\hline
\end{tabular}

$\mathrm{CI}=$ Confidence Interval $\mathrm{PCA}=$ patient controlled analgesia, $\mathrm{HTN}=$ hypertension, $\mathrm{DM}=$ diabetes mellitus, $\mathrm{RBC}=$ red blood cells.

Table 4: Association between PCA type and post-surgery prognosis in 1-to-1 propensity scorematched gastric cancer patients that underwent open gastrectomy

\begin{tabular}{lcccc}
\hline Outcome & $\begin{array}{c}\text { IV PCA } \\
(\boldsymbol{n}=\mathbf{3 7 3})\end{array}$ & $\begin{array}{c}\text { Epidural PCA } \\
(\boldsymbol{n}=\mathbf{3 7 3})\end{array}$ & $\begin{array}{c}\text { Hazard Ratio } \\
(\mathbf{9 5 \%} \text { CI) }\end{array}$ & $\boldsymbol{P}$-value \\
\hline Recurrence & & & $1.098(0.756-1.596)$ & 0.623 \\
No & $292(78.3)$ & $304(81.5)$ & & \\
Yes & $81(21.7)$ & $69(18.5)$ & & $0.855(0.391-1.869)$ \\
Mortality & & & 0.695 \\
No & $283(75.9)$ & $291(78.0)$ & & \\
Yes & $90(24.1)$ & $82(22.0)$ & & \\
\hline
\end{tabular}

Values are $n(\%)$ of patients $\mathrm{CI}=$ Confidence Interval, PCA $=$ patient controlled analgesia.

and gastric cancer prognosis. However, the present study seems to have great merit in that it is the first to include a very homogeneous group of patients from a reliable database of a high-volume center. Overlooking the importance of the nature of the surgical procedure as well as surgical technique can easily lead to incorrect interpretations in cancer patients. By including a homogeneous group of patients that underwent curative surgery, the present study was able to analyze the effect of epidural analgesia on recurrence after complete resection. Moreover, standardized extended (D2) lymphadenectomy was employed as a uniform surgical technique in all patients that were included in our analysis. Compared to limited (D1) lymphadenectomy, the D2 procedure has been proven to be associated with lower recurrence and gastriccancer-related mortality, and is currently recommended as the surgical approach of choice for patients with curable gastric cancer. [29] The good quality database and further PSM analysis that was used in the present study has been able to increase the reliability of our results. Whether epidural analgesia is able to affect length of survival or mortality in patients undergoing palliative or non-curative surgery requires future studies.

Despite the negative results of our study, it is difficult to conclude that regional techniques are not related to outcome after gastrectomy. One may suspect that isolated use of postoperative epidural analgesia without combining intraoperative epidural anesthesia is insufficient to induce effective immunomodulatory or anti-inflammatory effects. It seems most important to acknowledge that epidural analgesia is among the many different factors associated with perioperative anesthesia care that have been suggested to have effect on tumor progression and cancer prognosis. [27] It would be a futile attempt to improve cancer prognosis with a single drug or procedure, and therefore clinicians should be able to achieve good analgesia, and ameliorate perioperative stress and inflammation overall. [30]

The association between the use of norepinephrine and phenylephrine and greater hazard for mortality is most likely due to greater hemodynamic instability and hence the need for more vasopressors in patients with poorer general condition. Due to the retrospective design of the present analysis, we cannot conclude whether such drugs are definite causes of mortality or whether they are simply markers of worse clinical outcome. Among other perioperative drugs of interest, both aspirin [31, 32] and NSAIDs [33] showed no association with reduced recurrence or mortality. Interestingly, the use of labetalol, a non-selective $\beta$ adrenergic antagonist, was found to be associated with greater mortality after gastrectomy which is in contrary to previous reports. [34-36] However, the confidence interval was very wide, which indicates that our sample size was too small to draw conclusions in this aspect.

The major limitation of the present study is its retrospective nature, and thus its susceptibility to chance, bias and other confounding factors. However, we were 
able to include a relatively large number of patients from a single center, high-quality database in our analysis, and also performed propensity score matching with the available covariates to overcome potential selection bias somewhat. Although definitive data can only be provided by future RCTs, the results after propensity score matching in the present study should be able to add valuable insight to this debatable issue. Another limitation is that it is unclear how long the epidural catheters and PCA devices were maintained, and whether postoperative epidural analgesia was prematurely discontinued in patients included in the present analysis. Of note, it has been routine practice to start epidural PCA machines at the end of surgery and maintain infusion for 3 days in patients undergoing gastrectomies at our hospital. Also, intraoperative epidural infusions are rarely used. Therefore the results of the present study should be interpreted as a comparison between postoperative analgesic methods, and not as anesthesia. However, intermittent or complete discontinuation of epidural infusions due to hypotension or side effects of opioids are not uncommon in postoperative patients, and the absence of this data may have affected the results of our analysis.

In conclusion, postoperative epidural PCA does not seem to be associated with reduced recurrence or lower mortality in patients undergoing open curative gastrectomy for gastric cancer. Epidural analgesia should be employed as part of a comprehensive perioperative management plan, but should not be relied on as a beneficial factor for the prognosis after curative surgery in gastric cancer patients.

\section{MATERIALS AND METHODS}

\section{Study population and design}

This study is a retrospective analysis of patients that underwent open gastrectomy for gastric cancer with either IV or epidural PCA for postoperative pain control. The study protocol was approved by the Institutional Review Board and Hospital Research Ethics Committee of Severance Hospital, Yonsei University Health System (IRB \#4-2017-0392). The data collected for this study was from the electrical medical records of patients that underwent surgery between November 2005 and December 2010 at a single institution. Patients that received pre-operative chemotherapy or those that underwent non-curative surgery, cases that started as laparoscopic procedures but converted to laparotomy, electronic charts with unclear method of postoperative analgesia, and mortality cases that occurred within 30 days after surgery were excluded from analysis.

Retrieved demographic data of the patients included age, sex, height, weight, and comorbidities such as hypertension (HTN), diabetes mellitus (DM), pulmonary diseases, etc. In addition to type of PCA, cancer stage, extent of gastrectomy, type of anesthetic, common intraoperative drugs, and intraoperative colloid administration and red blood cell (RBC) transfusion were also analyzed as variables possibly associated with the prognosis of gastric cancer after open gastrectomy.

\section{Statistical analysis}

The primary outcome of this study was to compare the recurrence rate of gastric cancer between the two postoperative analgesia methods. Demographic and perioperative characteristics were analyzed using the Student's $t$-test for continuous variables and the chi-square test for categorical variables. Potential factors affecting cancer recurrence and mortality after gastrectomy were analyzed by the Cox proportional hazards model, and the risk of each variable was calculated as hazard ratio (HR) and 95\% confidence intervals (CIs). After screening for potentially significant variables with univariate analysis, multiple Cox regression analysis was done by including factors with $P$ values $<0.2$. Overall survival rates during the study period, and difference between survival curves according to PCA route were examined with the Kaplan-Meier logrank survival analysis method. Propensity score matching (PSM) was done to reduce selection bias, and confounders used for PSM included age, sex, body mass index, presence of DM and HTN. After 1:1 matching with propensity scores calculated with logistic regression analysis with aforementioned confounding factors, the risk of recurrence and mortality with each type of PCA was analyzed with conditional Cox proportional hazard regression. $P$ values less than 0.05 were considered as statistically significant. All analyses were done with SAS version 9.4.

\section{Abbreviations}

CI: confidence interval; DM: diabetes mellitus; HR: hazard ratio; HTN: hypertension; IRB: institutional review board; IV: intravenous; PCA: patient controlled analgesia; PSM: propensity score matching; RBC: red blood cell; $\mathrm{RCT}$ : randomized controlled trial.

\section{Author contributions}

S.S: Study design, data collection, data analysis, and writing the manuscript; H.I.K.: Data collection, data analysis and writing the manuscript; N.Y.K.: Study design, data collection and data analysis; K.Y.L: Study design and data analysis; D.W.K: Study design, data analysis, and writing the manuscript, Y.C.Y.: Study design, data collection, data analysis, and writing the manuscript.

\section{CONFLICTS OF INTEREST}

Drs Seokyung Shin, Hyoung-Il Kim, Na Young Kim, Ki-Young Lee, Dong Wook Kim and Young Chul Yoo have no conflicts of interest or financial ties to disclose. 


\section{FUNDING}

This study was supported solely by departmental resources of Severance Hospital, Yonsei University College of Medicine.

\section{REFERENCES}

1. Biki B, Mascha E, Moriarty DC, Fitzpatrick JM, Sessler DI, Buggy DJ. Anesthetic technique for radical prostatectomy surgery affects cancer recurrence: a retrospective analysis. Anesthesiology. 2008; 109:180-7. https://doi.org/10.1097/ ALN.0b013e31817f5b73.

2. Exadaktylos AK, Buggy DJ, Moriarty DC, Mascha E, Sessler DI. Can anesthetic technique for primary breast cancer surgery affect recurrence or metastasis? Anesthesiology. 2006; 105: 660-4.

3. Sessler DI. Does regional analgesia reduce the risk of cancer recurrence? A hypothesis. Eur J Cancer Prev. 2008; 17:26972. https://doi.org/10.1097/CEJ.0b013e3282f0c005.

4. Hiller JG, Hacking MB, Link EK, Wessels KL, Riedel BJ. Perioperative epidural analgesia reduces cancer recurrence after gastro-oesophageal surgery. Acta Anaesthesiol Scand. 2014; 58:281-90. https://doi.org/10.1111/aas.12255.

5. Wuethrich PY, Hsu Schmitz SF, Kessler TM, Thalmann GN, Studer UE, Stueber F, Burkhard FC. Potential influence of the anesthetic technique used during open radical prostatectomy on prostate cancer-related outcome: a retrospective study. Anesthesiology. 2010; 113:570-6. https://doi.org/10.1097/ALN.0b013e3181e4f6ec.

6. Tsui BC, Rashiq S, Schopflocher D, Murtha A, Broemling S, Pillay J, Finucane BT. Epidural anesthesia and cancer recurrence rates after radical prostatectomy. Can J Anaesth. 2010; 57:107-12. https://doi.org/10.1007/s12630-009-9214-7.

7. Lin L, Liu C, Tan H, Ouyang H, Zhang Y, Zeng W. Anaesthetic technique may affect prognosis for ovarian serous adenocarcinoma: a retrospective analysis. Br J Anaesth. 2011; 106:814-22. https://doi.org/10.1093/bja/aer055.

8. Forget P, Tombal B, Scholtes JL, Nzimbala J, Meulders C, Legrand C, Van Cangh P, Cosyns JP, De Kock M. Do intraoperative analgesics influence oncological outcomes after radical prostatectomy for prostate cancer? Eur J Anaesthesiol. 2011; 28:830-5. https://doi.org/10.1097/ EJA.0b013e32834b7d9a.

9. de Oliveira GS Jr, Ahmad S, Schink JC, Singh DK, Fitzgerald PC, McCarthy RJ. Intraoperative neuraxial anesthesia but not postoperative neuraxial analgesia is associated with increased relapse-free survival in ovarian cancer patients after primary cytoreductive surgery. Reg Anesth Pain Med. 2011; 36:271-7. https://doi.org/10.1097/ AAP.0b013e318217aada.

10. Capmas P, Billard V, Gouy S, Lhomme C, Pautier P, Morice $\mathrm{P}$, Uzan C. Impact of epidural analgesia on survival in patients undergoing complete cytoreductive surgery for ovarian cancer. Anticancer Res. 2012; 32:1537-42.
11. Heinrich S, Janitz K, Merkel S, Klein P, Schmidt J. Shortand long term effects of epidural analgesia on morbidity and mortality of esophageal cancer surgery. Langenbecks Arch Surg. 2015; 400:19-26. https://doi.org/10.1007/s00423014-1248-9.

12. Vogelaar FJ, Abegg R, van der Linden JC, Cornelisse HG, van Dorsten FR, Lemmens VE, Bosscha K. Epidural analgesia associated with better survival in colon cancer. Int J Colorectal Dis. 2015; 30:1103-7. https://doi.org/10.1007/ s00384-015-2224-8.

13. Zimmitti G, Soliz J, Aloia TA, Gottumukkala V, Cata JP, Tzeng CW, Vauthey JN. Positive Impact of Epidural Analgesia on Oncologic Outcomes in Patients Undergoing Resection of Colorectal Liver Metastases. Ann Surg Oncol. 2016; 23:1003-11. https://doi.org/10.1245/s10434-0154933-1.

14. Wang J, Guo W, Wu Q, Zhang R, Fang J. Impact of Combination Epidural and General Anesthesia on the LongTerm Survival of Gastric Cancer Patients: A Retrospective Study. Med Sci Monit. 2016; 22:2379-85.

15. Wang Y, Wang L, Chen $\mathrm{H}, \mathrm{Xu}$ Y, Zheng X, Wang G. The effects of intra- and postoperative anaesthesia and analgesia choice on outcome after gastric cancer resection : a retrospective study. Oncotarget. 2017; 8:62658-62665. https://doi.org/10.18632/oncotarget.16724.

16. Myles PS, Peyton P, Silbert B, Hunt J, Rigg JR, Sessler DI, Investigators AT, and ANZCA Trials Group Investigators. Perioperative epidural analgesia for major abdominal surgery for cancer and recurrence-free survival: randomised trial. BMJ. 2011; 342:d1491. https://doi.org/10.1136/bmj.d1491.

17. Scavonetto F, Yeoh TY, Umbreit EC, Weingarten TN, Gettman MT, Frank I, Boorjian SA, Karnes RJ, Schroeder DR, Rangel LJ, Hanson AC, Hofer RE, Sessler DI, et al. Association between neuraxial analgesia, cancer progression, and mortality after radical prostatectomy: a large, retrospective matched cohort study. Br J Anaesth. 2014; 113 1:i95-102. https://doi.org/10.1093/bja/aet467.

18. Tseng KS, Kulkarni S, Humphreys EB, Carter HB, Mostwin JL, Partin AW, Han M, Wu CL. Spinal anesthesia does not impact prostate cancer recurrence in a cohort of men undergoing radical prostatectomy: an observational study. Reg Anesth Pain Med. 2014; 39:284-8. https://doi. org/10.1097/AAP.0000000000000108.

19. Ehdaie B, Sjoberg DD, Dalecki PH, Scardino PT, Eastham JA, Amar D. Association of anesthesia technique for radical prostatectomy with biochemical recurrence: a retrospective cohort study. Can J Anaesth. 2014; 61:1068-74. https://doi. org/10.1007/s12630-014-0221-y.

20. Sprung J, Scavonetto F, Yeoh TY, Kramer JM, Karnes RJ, Eisenach JH, Schroeder DR, Weingarten TN. Outcomes after radical prostatectomy for cancer: a comparison between general anesthesia and epidural anesthesia with fentanyl analgesia: a matched cohort study. Anesth Analg. 2014; 119:859-66. https://doi.org/10.1213/ ANE.0000000000000320. 
21. Cummings KC 3rd, Xu F, Cummings LC, Cooper GS A comparison of epidural analgesia and traditional pain management effects on survival and cancer recurrence after colectomy: a population-based study. Anesthesiology. 2012; 116:797-806. https://doi.org/10.1097/ ALN.0b013e31824674f6.

22. Gupta A, Bjornsson A, Fredriksson M, Hallbook O, Eintrei C. Reduction in mortality after epidural anaesthesia and analgesia in patients undergoing rectal but not colonic cancer surgery: a retrospective analysis of data from 655 patients in central Sweden. Br J Anaesth. 2011; 107:164-70. https://doi.org/10.1093/bja/aer100.

23. Holler JP, Ahlbrandt J, Burkhardt E, Gruss M, Rohrig R, Knapheide J, Hecker A, Padberg W, Weigand MA. Peridural analgesia may affect long-term survival in patients with colorectal cancer after surgery (PACO-RAS-Study): an analysis of a cancer registry. Ann Surg. 2013; 258:989-93. https://doi.org/10.1097/SLA.0b013e3182915f61.

24. Gottschalk A, Ford JG, Regelin CC, You J, Mascha EJ, Sessler DI, Durieux ME, Nemergut EC. Association between epidural analgesia and cancer recurrence after colorectal cancer surgery. Anesthesiology. 2010; 113:27-34. https://doi.org/10.1097/ALN.0b013e3181de6d0d.

25. Cummings KC 3rd, Patel M, Htoo PT, Bakaki PM, Cummings LC, Koroukian S. A comparison of the effects of epidural analgesia versus traditional pain management on outcomes after gastric cancer resection: a population-based study. Reg Anesth Pain Med. 2014; 39:200-7. https://doi. org/10.1097/AAP.0000000000000079.

26. Piegeler T, Beck-Schimmer B. Anesthesia and colorectal cancer - The perioperative period as a window of opportunity? Eur J Surg Oncol. 2016; 42:1286-95. https:// doi.org/10.1016/j.ejso.2016.05.004.

27. Sekandarzad MW, van Zundert AAJ, Lirk PB, Doornebal CW, Hollmann MW. Perioperative Anesthesia Care and Tumor Progression. Anesth Analg. 2017; 124:1697-708. https://doi.org/10.1213/ANE.0000000000001652.

28. Le-Wendling L, Nin O, Capdevila X. Cancer Recurrence and Regional Anesthesia: The Theories, the Data, and the Future in Outcomes. Pain Med. 2016; 17:756-75. https:// doi.org/10.1111/pme.12893.

29. Songun I, Putter H, Kranenbarg EM, Sasako M, van de Velde CJ. Surgical treatment of gastric cancer: 15-year follow-up results of the randomised nationwide Dutch
D1D2 trial. Lancet Oncol. 2010; 11:439-49. https://doi. org/10.1016/S1470-2045(10)70070-X.

30. Ash SA, Buggy DJ. Does regional anaesthesia and analgesia or opioid analgesia influence recurrence after primary cancer surgery? An update of available evidence. Best Pract Res Clin Anaesthesiol. 2013; 27:441-56. https://doi. org/10.1016/j.bpa.2013.10.005.

31. Bosetti C, Rosato V, Gallus S, Cuzick J, La Vecchia C. Aspirin and cancer risk: a quantitative review to 2011. Ann Oncol. 2012; 23:1403-15. https://doi.org/10.1093/annonc/ mds 113 .

32. Trabert B, Ness RB, Lo-Ciganic WH, Murphy MA, Goode EL, Poole EM, Brinton LA, Webb PM, Nagle CM, Jordan SJ, Risch HA, Rossing MA, Doherty JA, et al, and Australian Ovarian Cancer Study Group, Australian Cancer Study (Ovarian Cancer), and Ovarian Cancer Association Consortium. Aspirin, nonaspirin nonsteroidal anti-inflammatory drug, and acetaminophen use and risk of invasive epithelial ovarian cancer: a pooled analysis in the Ovarian Cancer Association Consortium. J Natl Cancer Inst. 2014; 106:djt431. https://doi.org/10.1093/jnci/djt431.

33. Ruder EH, Laiyemo AO, Graubard BI, Hollenbeck AR, Schatzkin A, Cross AJ. Non-steroidal anti-inflammatory drugs and colorectal cancer risk in a large, prospective cohort. Am J Gastroenterol. 2011; 106:1340-50. https://doi. org/10.1038/ajg.2011.38.

34. Watkins JL, Thaker PH, Nick AM, Ramondetta LM, Kumar S, Urbauer DL, Matsuo K, Squires KC, Coleman RL, Lutgendorf SK, Ramirez PT, Sood AK. Clinical impact of selective and nonselective beta-blockers on survival in patients with ovarian cancer. Cancer. 2015; 121:3444-51. https://doi.org/10.1002/cncr.29392.

35. Powe DG, Voss MJ, Zanker KS, Habashy HO, Green AR, Ellis IO, Entschladen F. Beta-blocker drug therapy reduces secondary cancer formation in breast cancer and improves cancer specific survival. Oncotarget. 2010; 1:628-38. https://doi.org/10.18632/oncotarget.101009.

36. Kim YS, Kang SH, Song KY, Cho ML, Her YM, Huh JW, Lee J. The immunomodulatory role of esmolol in patients undergoing laparoscopic gastrectomy due to gastric cancer. Anaesthesia. 2013; 68:924-30. https://doi.org/10.1111/ anae.12229. 